\title{
A Rare Presentation of Intraorbital Abducens Nerve Schwannoma
}

\section{Gaurav Garg*, Rukmendra Pratap Singh Warkade, Narendra Patidar, Ranu Gupta and Harshdeep Singh Gabba}

\author{
Department of Orbit and Oculoplasty, Shri Sadguru Seva Sangh Trust, Chitrakoot, \\ India
}

*Corresponding Author: Gaurav Garg, Clinical Associate, Department of Orbit and Oculoplasty, Sadguru Netra Chikitsalaya, Chitrakoot, India.
Received: July 23, 2021

Published: August 19, 2021

(C) All rights are reserved by Gaurav Garg., et al.

\begin{abstract}
Schwannomas are slow-growing, well-defined, and pseudo-encapsulated arising from the Schwann cells of the peripheral nerves. Usually, schwannomas are presented intracranially. Intraorbital schwannomas' incidence is as low as 1-2\% of all orbital tumors. Abducens nerve schwannoma in the orbit originating from the terminal branches which supply to the lateral rectus is extremely rare.

A 45-year-old lady presented with painful proptosis of $10 \mathrm{~mm}$ with no extraocular muscle movement restriction. She underwent lateral orbitotomy with excision biopsy and was histopathologically diagnosed as schwannoma. On follow-up, she had total recovery of the abducens nerve.
\end{abstract}

Keywords: Schwannoma; Intraorbital Schwannoma; Abducens Nerve Schwannoma; Orbital Schwannoma; Painful Schwannoma

\section{Introduction}

Schwannomas arise from the Schwann cells of the myelin sheath of the peripheral nerves as a benign neurogenic tumor [1]. They are well-defined, pseudo-encapsulated, slow-growing arising from the sheath of the fascicle and present as eccentrically [2]. It can present as either isolated schwannoma, in association with von Recklinghausen syndrome, or as schwannomatosis [3]. Incidence of intraorbital schwannomas is as low as $1-2 \%$ of all orbital tumors [4]. Abducens nerve schwannoma in the orbit originating from the terminal branches which supply to the lateral rectus is extremely rare [1]. Herein we describe a case of intraorbital abducens nerve schwannoma.

Note

This report adhered to the ethical principles outlined in the Declaration of Helsinki as amended in 2013. Informed consent was obtained from the patient to publish this case report and her images. She was informed that her identity and personal details will be kept confidential.

\section{Case Report}

A 45-year-old Asian Indian lady presented to our tertiary eye center with complaints of pain and protrusion of the right eye for the last 3 months. There was no history of trauma, redness, double vision, postural variation, diurnal variation, or a variation on the Valsalva maneuver in the right eye. On examination, the left eye had a normal anterior and posterior segment with a vision of $6 / 6$. Whereas in the right eye, the uncorrected vision was 5/60 with $+3.50 \mathrm{D}$ correction it improved to 6/9 suggesting compression of the globe making it hyperopic. Contrast sensitivity decreased to 1.50. Anterior segment examination was found to be normal whereas the posterior segment showed choroidal folds with disc edema. On proptosis evaluation of the right eye, there was a relative proptosis of $10 \mathrm{~mm}$ with a positive retropulsion test. Extraocular muscle movements were full and free. Ultrasonography B-scan of the orbit showed a large hypoechoic lesion with a hyperechoic outer layer suggestive of a solid lesion temporal to the optic nerve with its compression. A Computed Tomography scan showed a mildly enhancing well-defined lesion in the intraconal region compressing the optic nerve and globe with lateral rectus and superior rectus displaced laterally. The lesion was of size 25.1 x $25.2 \mathrm{~mm}$.

Because of a vision-threatening condition, she underwent an excisional biopsy via superolateral orbitotomy with modified Stallard 
Wright's incision using a trans-periosteal approach. Cryo-assisted removal was done after medialising the optic nerve. Post-operatively she was treated with antibiotics and steroids. On follow-up, she has developed partial lateral gaze palsy initially because of the removal of the abducens nerve, which was recovered in the due course. Her cutaneous and corneal sensations in the area of trigeminal nerve were intact, pupil, levator palpebral superioris action, rest of the extraocular muscle movements were intact.

On histopathology, the microscopic section revealed a capsulated tumor with predominantly Antoni 'A' area showing wavy spindle cells arranged in palisading fashion with verocay bodies. Spindle tumor cells were seen with elongated nuclei with moderate nuclear, cellular pleomorphism, and inconspicuous nucleoli along with the mitotic activity of $<4 / 10$ high power field. The lesion had a strong reactivity with S-100. There was no Antoni 'B' area seen suggestive of benign cellular schwannoma (Figure $C$ and D).

\section{Discussion and Conclusion}

Schwannomas are eccentrically growing, gradually progressive tumors arising from Schwann cells present on the sheath of peripheral nerves, as a well-defined lesion with pseudo-encapsulation. They are more commonly found in the head and neck. Incidence of intraorbital schwannomas accounts for $1-2 \%$ of all orbital tumors among which mostly originate from the branches of oculomotor, trochlear, trigeminal, and abducens nerves and sympathetic and parasympathetic fibers. Abducens nerve schwannomas are extremely rare.

Table 1 [1-3,5-8] represents the previously published data on the intraorbital schwannomas. In the present case report, the pa-

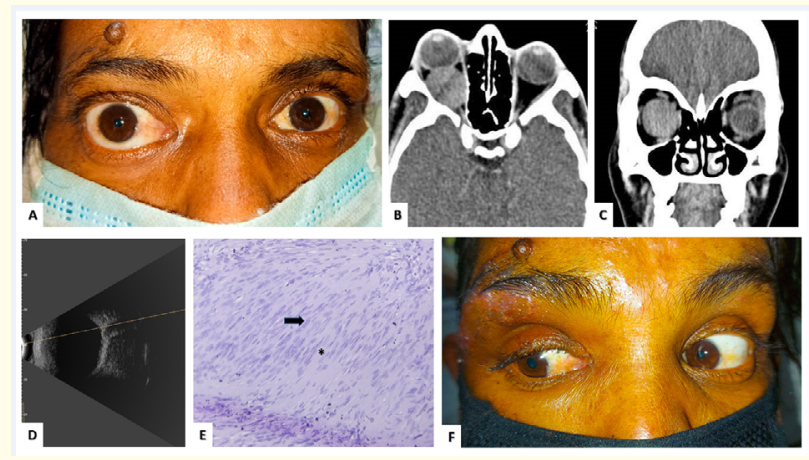

Figure 1: A: Clinical image showing proptosis of the right eye. B: Axial cut of Computed Tomography scan of orbit showing a large well-defined lesion with bowing of both the lateral and medial walls with indentation of the globe. C: Coronal cut of Computed Tomography scan of orbit showing its as intraconal with medialisation of the optic nerve to inferomedial location. D: Ultrasonography B-scan of orbit showing a large lesion with hyperechoic outer layer followed by hypoechoic part suggestive of solid lesion indenting the globe. E: Histopathological image showing Antoni 'A' area composed of wavy spindle nuclei with nuclear palisading (black arrow) and verocay bodies (asterisk) under high power magnification. F: Clinical image showing recovering lateral gaze palsy on follow-up.

tient presented with only painful proptosis and optic disc edema with no lateral rectus palsy.

On reviewing the literature, it can be seen that when tumor size was $45 \mathrm{~mm}$, there was only a partial recovery of the lateral rectus

\begin{tabular}{|c|c|c|c|c|c|c|c|c|c|}
\hline Case & Author & Year & Age/Sex & Presentation & $\begin{array}{c}\text { Tumor Size } \\
\text { (mm) }\end{array}$ & $\begin{array}{c}\text { Tumor } \\
\text { Type }\end{array}$ & $\begin{array}{c}\text { Surgical } \\
\text { Approach }\end{array}$ & Resection & $\begin{array}{l}\text { VI nerve } \\
\text { recovery }\end{array}$ \\
\hline & Jack Rootman [5] & 1982 & $60 / \mathrm{M}$ & $\begin{array}{c}\text { LR palsy, Painless } \\
\text { proptosis }\end{array}$ & $\mathrm{N} / \mathrm{A}$ & Solid & $\begin{array}{c}\text { Lateral } \\
\text { Orbitotomy }\end{array}$ & Total & Total \\
\hline & Irace [6] & 2008 & $55 / \mathrm{M}$ & $\begin{array}{c}\text { LR palsy, Painless } \\
\text { proptosis }\end{array}$ & $\mathrm{N} / \mathrm{A}$ & Solid & $\begin{array}{c}\text { Lateral } \\
\text { Orbitotomy }\end{array}$ & Total & Partial \\
\hline & Rato [3] & 2012 & $42 / \mathrm{M}$ & $\begin{array}{c}\text { LR palsy, Painful } \\
\text { Proptosis }\end{array}$ & 22 & Cystic & $\begin{array}{c}\text { Lateral } \\
\text { Orbitotomy }\end{array}$ & Total & Total \\
\hline & Feichtinger [7] & 2013 & $53 / F$ & $\begin{array}{c}\text { LR paresis, optic } \\
\text { atrophy }\end{array}$ & $45 \times 20 \times 15$ & Solid & $\begin{array}{c}\text { Lateral } \\
\text { Orbitotomy }\end{array}$ & Partial & Partial \\
\hline & Bhaganagare [8] & 2015 & $32 / F$ & Pain & 21 & Solid & $\begin{array}{c}\text { Superior } \\
\text { Orbitotomy }\end{array}$ & Total & Preserved \\
\hline & Lida [2] & 2016 & $51 / \mathrm{M}$ & $\begin{array}{c}\text { Retinal } \\
\text { Detachment }\end{array}$ & 10 & Solid & $\begin{array}{c}\text { Lateral } \\
\text { Orbitotomy }\end{array}$ & Total & Preserved \\
\hline & $\operatorname{Li}[1]$ & 2018 & $54 / \mathrm{M}$ & $\begin{array}{c}\text { LR palsy, Painless } \\
\text { proptosis }\end{array}$ & $20 \times 10 \times 6$ & Solid & $\begin{array}{c}\text { Lateral } \\
\text { Orbitotomy }\end{array}$ & Total & Total \\
\hline & Present & & $45 / F$ & $\begin{array}{l}\text { Painful Proptosis, } \\
\text { Optic disc edema }\end{array}$ & $25.1 \times 25.2$ & Solid & $\begin{array}{c}\text { Lateral } \\
\text { Orbitotomy }\end{array}$ & Total & Total \\
\hline
\end{tabular}

Table 1: Previous literature on intraorbital abducens nerve schwannomas. 
muscle palsy after complete excision whereas when it was $\leq 25 \mathrm{~mm}$, there was complete recovery of the function of the abducens nerve. Thereby emphasizing the need for diagnosis and surgical management in an early stage for the functional preservation of the abducens nerve.

\section{Bibliography}

1. Li G., et al. "Orbital schwannoma of abducens nerve: a case report and literature review" 7 .

2. Iida Y., et al. "Orbital Abducens Nerve Schwannoma: A Case Report and Review of the Literature". NMC Case Reports Journal 3.4 (2016): 107-109.

3. Rato RMF, et al. "Intraorbital abducens nerve schwannoma". World Neurosurgery 78.3-4 (2012): 375.e1-4.

4. Wang $\mathrm{Y}$ and Xiao LH. "Orbital schwannomas: findings from magnetic resonance imaging in 62 cases". Eye Lond Engl. 22.8 (2008): 1034-1039.

5. Rootman J., et al. "Primary orbital schwannomas". British Journal of Ophthalmology 66.3 (1982): 194-204.

6. Irace C., et al. "Isolated intraorbital schwannoma arising from the abducens nerve". Acta Neurochirie (Wien) 150 (2008): 1209-1210.

7. Feichtinger M., et al. "Intraorbital Schwannoma of the Abducens Nerve: Case Report". Journal of Oral and Maxillofacial Surgery 71.2 (2013): 443-445.

8. Bhaganagare AS., et al. "Orbital intraconal abducens nerve schwannoma: A case report and review of the literature". Asian Journal of Neurosurgery 10.1 (2015): 61.

Volume 5 Issue 9 September 2021

(C) All rights are reserved by Gaurav Garg., et al. 